\title{
Proceeding
}

9th INSHS International Christmas Sport Scientific Conference, 4-6 December 2014. International Network of Sport and Health

Science. Szombathely, Hungary

\section{Dynamic stretching versus static stretching in gymnastic performance}

\author{
CRISTIANA D'ANNA , FILIPPO GOMEZ PALOMA \\ Department of Human, Philosophical and Education Science, University of Salerno, Fisciano, Italy
}

\begin{abstract}
D'Anna, C., \& Gomez, F. (2015). Dynamic stretching versus static stretching in gymnastic performance. A brief review. J. Hum. Sport Exerc., 9(Proc1), pp.S437-S446. Different types of stretching techniques are commonly performed in the gymnastic training sessions. Flexibility is one of the essential aspects of this sport like so the explosive strength but actually there is a limited literature assessing the effectiveness of the specific technique to increase the range of motion and, at the same time, to improve the explosive performance. The aim of this study was to conduct a brief analysis of the literature to understand how to plan the training programs finalized to improve the gymnastic performance (Gomez Paloma F., Rio L., D'Anna C. 2014). The MEDLINE and SportDiscus databases were searched for relevant literature using textwords for English-language articles related to stretching, flexibility, explosive strength, dynamic/static stretching and gymnastic. Additional references were reviewed from the bibliographies and from citation searches on key articles. Twenty-two articles were examined, of which two reviews, one roundtable discussion of flexibility training, two specific studies on gymnastics, two on basketball, one on baseball and the remaining articles focusing on the flexibility and the jumping performance in general. In accordance to several studies analyzed, the research carries out some reflections on different stretching techniques included in the training phases of gymnastics (warming-up, cooling down) useful in planning the training sessions finalized to the best performance. These are fundamental aspects to highlight and emphasize the consequences of the use of the different techniques especially regarding the duration and the intensity of the exercises choice. Key words: GYMNASTIC, STATIC AND DYNAMIC STRETCHING, FLEXIBILITY, JUMP.
\end{abstract}

Corresponding author. University La Sabana, Puente Del Comun, Chia, Cundinamarca, Colombia E-mail: preparacionfisica2@gmail.com 9th INSHS International Christmas Sport Scientific Conference, 4-6 December 2014. International Network of Sport and Health Science. Szombathely, Hungary.

JOURNAL OF HUMAN SPORT \& EXERCISE ISSN 1988-5202

(c) Faculty of Education. University of Alicante

doi:10.14198/jhse.2015.10.Proc1.37 


\section{INTRODUCTION}

The flexibility is commonly considered an essential aspect of gymnastics training and performance. Flexibility is always included in the battery test to identify the potentiality and evaluate the level of the athletes' skills. In spite of a fairly universal recognition of the need for flexibility in gymnastics, surprisingly little research has been done on enhancing flexibility amongst elite performers. In the last twenty years several studies there have been conducted on training of the flexibility and stretching techniques but most of these focused only on the consequences of these techniques on the explosive strength.

In gymnastics the problem of increasing flexibility is more complicated because athletes must have the use of both flexibility and strength in the same technical act.

The gymnastics code of points of the different kind of disciplines makes a deductions if the gymnast cannot achieve a specific position or does not perform a broad jump with the perfect alignment of the legs in the maximal amplitude. That range of motion dependent on both strength and flexibility is commonly understood, but how to train both qualities has not been well researched.

It's important to underline that during the training section the various techniques of stretching activities have the greatest percentage of training time, but the coach doesn't understand why the gymnasts are sometimes evaluated as being inflexible.

In the specific training methodology currently there is a little confusion (Raiola, Scassillo, Parisi, \& Di Tore, 2013). Trainers and technical staff have different views about the benefits and negative consequences of stretching techniques and therefore the methods chosen are subject to personal experience rather than scientific accuracy.

Further studies are necessary non only focused on stretching techniques, but also for each gymnastics discipline in the Gymnastic Federation (aerobic, artistic and rhythmic) which differ between each other.

Thus to guide towards the best training methods to be used in order to improve the flexibility and strength. Warm-up is usually composed of a sub maximal aerobic activity, stretching of the major muscle group, as well as general and specific sport exercises performed intensively as training for competitions (Taylor et al., 2008). Several studies have shown that stretching following submaximal aerobic activity increases ranges of motion and enhances performance (Magnusson \& Restrom, 2006; Young \& Behm, 2002).

Previous studies, reported that static stretching may temporary decrease the ability of the stretched muscles to generate power output (Behm et al. 2001).

The duration and intensity of the static stretching exercises seem to play a critical role in these impairments, with long lasting, intense stretching resulting in a greater decrease in subsequent power generating ability (Behm \& Chaouachi, 2011).

In most studies, static stretching may increase compliance and thus reduce the stiffness of the muscle tendon unit, but this effect is transient (Magnusson \& Renstrom, 2006) and depends on the duration and intensity of the stretching protocols. 
The combined effects of stretching and conditioning exercises during warm- up may be influenced by the flexibility and muscle power of the perfomer, as well as by the volume of exercise.

Gymnastic is a sport that is generally characterized by high level of strength and power relative to body weight, as well as high flexibility (Arkaev \& Sustslin, 2004).

Therefore, the aim of the present study is to conduct a brief analysis of the literature to understand which are the benefits and the negative aftermaths of the different types of stretching techniques to plan the training programs finalized to improve the gymnastic performance.

\section{METHODS}

The MEDLINE and SportDiscus databases were searched for relevant literature using textwords for English-language articles related to stretching, flexibility, explosive strength, dynamic/static stretching and gymnastic. Additional references were reviewed from the bibliographies and from citation searches on key articles.

Twenty-two articles were examined, of which two reviews, one roundtable discussion of flexibility training, two specific studies on gymnastics, two on basketball, one on baseball and the remaining articles focusing on the flexibility and the jumping performance in general. 
Table 1. Summary of literature review

\begin{tabular}{|c|c|c|c|c|}
\hline Title & $\begin{array}{l}\text { Author, } \\
\text { Year }\end{array}$ & $\begin{array}{l}\text { Type of } \\
\text { Study }\end{array}$ & Main results & Performance \\
\hline $\begin{array}{l}\text { Acute effects of static and ballistic } \\
\text { stretching on measures of strength and } \\
\text { power }\end{array}$ & $\begin{array}{l}\text { Samuel et } \\
\text { al. (2008) }\end{array}$ & $\begin{array}{l}\text { Cross- } \\
\text { sectional } \\
\text { study }\end{array}$ & $\begin{array}{l}\text { Dynamic stretching can function to properly prepare the athlete's } \\
\text { body for dynamic movements without the stretch-induced } \\
\text { decrements that have been seen with pre-activity static and ballistic } \\
\text { stretching by improving performance. }\end{array}$ & \begin{tabular}{lc}
\multicolumn{3}{l}{ On strength and Power } \\
-Dynamic & $\uparrow$ \\
-Static & $\downarrow$ \\
-Ballistic & $\downarrow$
\end{tabular} \\
\hline $\begin{array}{l}\text { Ballistic stretching increases flexibility } \\
\text { and acute vertical jump height when } \\
\text { combined with basketball activity }\end{array}$ & $\begin{array}{l}\text { Woolstenh } \\
\text { ulme et al. } \\
(2006)\end{array}$ & $\begin{array}{l}\text { Cross- } \\
\text { sectional } \\
\text { study }\end{array}$ & $\begin{array}{l}\text { Ballistic stretching can be safely and effectively used as a warm-up } \\
\text { for basketball play. Ballistic stretching used as part of a warm-up for } \\
\text { basketball play increases vertical jump performance. }\end{array}$ & $\begin{array}{l}\text { On vertical Jump } \\
\text { - Ballistic } \\
\text { (in warm up) }\end{array}$ \\
\hline $\begin{array}{l}\text { Decrements in Stiffness are restored } \\
\text { within } 10 \mathrm{~min}\end{array}$ & $\begin{array}{l}\text { Mizuno et } \\
\text { al. }(2013)\end{array}$ & $\begin{array}{l}\text { Cross } \\
\text { sectional } \\
\text { study }\end{array}$ & $\begin{array}{l}1 \text { min of static stretching at maximal dorsiflexion repeated } 5 \text { times } \\
\text { can reduce stiffness in the MTU (muscle-tendon unit), but this effect } \\
\text { disappears within } 10 \text { min. }\end{array}$ & $\begin{array}{l}\text { On stiffness } \\
\text {-Static } \quad \downarrow \\
\text { (the effect disappears whithin } 10 \mathrm{~min} \text {.) }\end{array}$ \\
\hline Does Stretching Improve Performance? & $\begin{array}{l}\text { Shrier } \\
(2004)\end{array}$ & $\begin{array}{l}\text { Systematic } \\
\text { Review of } \\
\text { the } \\
\text { Literature }\end{array}$ & $\begin{array}{l}\text { Static Stretching immediately prior to exercise decreases the results } \\
\text { on performance tests that require isolated force or power. The effect } \\
\text { on running speed remains to be determined. }\end{array}$ & $\begin{array}{l}\text { On force and power } \\
\text { - Static } \quad \downarrow \\
\text { On running speed } \\
\text {-Static } \quad ?\end{array}$ \\
\hline $\begin{array}{l}\text { Dynamic vs. Static-stretching warm up: } \\
\text { the effect on power and agility } \\
\text { performance }\end{array}$ & $\begin{array}{l}\text { McMillian } \\
\text { et al. } \\
(2006)\end{array}$ & $\begin{array}{l}\text { Cross } \\
\text { sectional } \\
\text { study }\end{array}$ & $\begin{array}{l}\text { For tasks requiring power and agility, the results suggest that a } \\
\text { dynamic warm up might offer performance benefits not found with } \\
\text { static stretching or no warm up. It is likely that a DWU similar to that } \\
\text { used in this study will achieve general warm up goals without } \\
\text { invoking the mechanical and neural activation drawbacks associated } \\
\text { with acute, static-stretching. For tasks demanding a high degree of } \\
\text { flexibility, power, and agility, warm up activities should be } \\
\text { sequenced so that static-stretching (if it is deemed necessary) is } \\
\text { followed by dynamic and progressive movements. }\end{array}$ & $\begin{array}{ll}\text { On power and agility } \\
\text {-Dinamic } & \uparrow \\
\text {-No warm up } & \downarrow \\
\text {-Static } & \downarrow\end{array}$ \\
\hline $\begin{array}{l}\text { Effects of baseline levels of flexibility } \\
\text { and vertical jump ability on performance } \\
\text { following different volumes of static } \\
\text { stretching and potentiating exercises in } \\
\text { elite gymnasts }\end{array}$ & $\begin{array}{l}\text { Donti et al. } \\
(2014)\end{array}$ & $\begin{array}{l}\text { Cross } \\
\text { sectional } \\
\text { study }\end{array}$ & $\begin{array}{l}\text { The baseline levels of flexibility and vertical jump ability do not affect } \\
\text { the acute responses to stretching and muscle conditioning activities, } \\
\text { aiming to increase ROM and CMJ in elite gymnasts. } \\
\text { Gymnasts with widely different flexibility and CMJ performance } \\
\text { levels respond similarly to static stretching and PAP interventions } \\
\text { during warm-up. } \\
30 \text { " of static stretching to the point of discomfort may be } \\
\text { incorporated in the warm-up of elite gymnasts, without impairing } \\
\text { subsequent explosive performance. CMJ performance can increase } \\
\text { considerably, if three sets of } 5 \text { tuck jumps are also performed after } \\
\text { stretching. }\end{array}$ & $\begin{array}{l}\text { On vertical jump and flexibility } \\
- \text { Static - } \\
-30 \text { " Static in warm-up } \rightarrow \text { no impairing } \\
\text { the performance } \\
-30 \text { " static }+3 \times 5 \text { sets TJ } \uparrow\end{array}$ \\
\hline $\begin{array}{l}\text { Effects of dynamic warm-up on lower } \\
\text { body explosiveness among collegiate } \\
\text { baseball players. }\end{array}$ & $\begin{array}{l}\text { Frantz et } \\
\text { al. }(2011)\end{array}$ & $\begin{array}{l}\text { Cross } \\
\text { sectional } \\
\text { study }\end{array}$ & $\begin{array}{l}\text { The results show that static warm-up decreases vertical jump height } \\
\text { by } 1.30 \mathrm{~cm} \\
\text { ( } 0.51 \mathrm{in} .) \text {, and dynamic increases it by } 3.77 \mathrm{~cm}(1.48 \mathrm{in} .) \text {; if this is } \\
\text { the case, then an athlete can gain nearly } 2 \mathrm{in} \text {. on his vertical by } \\
\text { simply switching from a static warm-up routine to a dynamic routine. } \\
\text { This study illustrates that dynamic warm-up positively impacts lower } \\
\text { body explosiveness among collegiate baseball players. }\end{array}$ & $\begin{array}{lr}\text { On vertical Jump } \\
\text { - Static } & \downarrow \\
\text { - Dynamic } & \uparrow\end{array}$ \\
\hline
\end{tabular}




\begin{tabular}{|c|c|c|c|c|}
\hline $\begin{array}{l}\text { Effects of static and dynamic stretching } \\
\text { on Sprint and jump performance in boys } \\
\text { and girls }\end{array}$ & $\begin{array}{l}\text { Paradisis } \\
\text { et } \quad \text { al. } \\
(2013)\end{array}$ & $\begin{array}{l}\text { Cross } \\
\text { sectional } \\
\text { study }\end{array}$ & $\begin{array}{l}\text { Sprinting and explosive power performances are negatively affected } \\
\text { if SS precedes these tasks. Therefore, SS should be avoided before } \\
\text { these exercises. Dynamic stretching does not inhibit sprinting } \\
\text { performance but deteriorates explosive power. Therefore, DS could } \\
\text { be included before tasks that involve sprinting; however, it should be } \\
\text { avoided before tasks that involve jumping. Both SS and DS improve } \\
\text { flexibility, even though it seems the SS is more efficient compared } \\
\text { with DS. }\end{array}$ & $\begin{array}{l}\text { On sprint and explosive power } \\
\text { performance } \\
\text { - Static } \quad \downarrow \\
\text { - Dynamic on sprint - } \\
\text { - Dynamic on E.Power } \downarrow \\
\text { On flexibility } \\
\text {-Static } \uparrow \\
\text {-Dynamic } \uparrow\end{array}$ \\
\hline Enhancing flexibility in gymnastics & $\begin{array}{l}\text { Sands } \\
(1999)\end{array}$ & $\begin{array}{l}\text { Cross } \\
\text { sectional } \\
\text { study }\end{array}$ & $\begin{array}{l}\text { The results of this study showed that split leap range of motion can } \\
\text { be improved. } \\
\text { The lack of a control group (which would have tested but not } \\
\text { participated in the Theraband stretching) results in an inability to } \\
\text { state with certainty the cause of the enhanced split leap } \\
\text { performances. However, the cause effect relationship is } \\
\text { strengthened by the temporal ordering of events and the novel } \\
\text { nature of the split leap. }\end{array}$ & $\begin{array}{l}\text { On flexibility } \text { and jump } \\
\text {-Dynamic } \uparrow\end{array}$ \\
\hline $\begin{array}{lll}\begin{array}{l}\text { Roundtable } \\
\text { training }\end{array} & \text { discussion: } & \text { Flexibility } \\
& & \\
\end{array}$ & $\begin{array}{l}\text { Haff } \\
(2006)\end{array}$ & $\begin{array}{l}\text { Roundtabl } \\
\text { e } \\
\text { discussion }\end{array}$ & $\begin{array}{l}\text { Ballistic may cause injury to the muscle, tendons or ligaments being } \\
\text { stretched. } \\
\text { Several studies have indicated that PNF S. is more effective in } \\
\text { improving flexibility, whereas other studies have shown no } \\
\text { superiority of PNF over static or ballistic techniques. PNF should be } \\
\text { contraindicated before exercise or performance because it masks } \\
\text { the protective mechanism of pain. } \\
\text { Static } s \text {. induced increases in ROM are volume dependent. The } \\
\text { effect of static } s \text {. on performance are not clear because there are } \\
\text { contrasting studies. }\end{array}$ & $\begin{array}{l}\text { On Flexibility } \\
\text { Ballistic - NO } \\
\text { Static, Dynamic and PNF to prefer } \\
P N F \text { no positive in warmup } \\
\text { Static } \quad \uparrow\end{array}$ \\
\hline $\begin{array}{l}\text { Should static stretching be used during } \\
\text { a warm-up for strength and power } \\
\text { activities? }\end{array}$ & $\begin{array}{l}\text { Warren } \\
(2002)\end{array}$ & $\begin{array}{l}\text { Cross } \\
\text { sectional } \\
\text { study }\end{array}$ & $\begin{array}{l}\text { Substantial evidence is now available to state that static stretching } \\
\text { can impair strength and power performance, although the duration } \\
\text { of the impairment, the exact stretching protocols, and the } \\
\text { physiological mechanisms are not yet known. }\end{array}$ & $?$ \\
\hline $\begin{array}{l}\text { Static stretching can impair explosive } \\
\text { performance for at least } 24 \text { hours }\end{array}$ & $\begin{array}{l}\text { Haddad } \\
(2013)\end{array}$ & $\begin{array}{l}\text { Cross } \\
\text { sectional } \\
\text { study }\end{array}$ & $\begin{array}{l}\text { Sprint performances }(10,20 \text {, and } 30 \mathrm{~m}) \text { and horizontal jumps } 24 \\
\text { hours after the DS were significantly better than those after the no- } \\
\text { stretch CC and SS. Results of this study demonstrated the negative } \\
\text { effect of SS up to } 24 \text {-hour post-stretching }\end{array}$ & $\begin{array}{l}\text { On sprint performance } \\
\text {-Dynamic } \quad \uparrow 24 h \text { after } \\
\text {-Static } \quad \downarrow 24 h \text { after } \\
\text {-No stretching } \downarrow\end{array}$ \\
\hline $\begin{array}{l}\text { Stretching-induced deficit of maximal } \\
\text { Isometric torque is restored within } 10 \\
\text { minutes. }\end{array}$ & $\begin{array}{l}\text { Mizuno } \\
(2013)\end{array}$ & $\begin{array}{l}\text { Cross } \\
\text { sectional } \\
\text { study }\end{array}$ & $\begin{array}{l}\text { Static 5-minute stretching decreases maximal isometric plantar } \\
\text { strength immediately after stretching. A warm-up consisting of static } \\
\text { stretching and activity and movement renders the stretching-induced } \\
\text { force deficit practically ineffectual. Athletes should not perform static } \\
\text { stretching within } 10 \text { minutes before a competition if they do not want } \\
\text { to decrease maximal isometric plantar strength after static } \\
\text { stretching. }\end{array}$ & $\begin{array}{l}\text { On the isometric strength } \\
\text {-Static } 5 \mathrm{~min} \downarrow \\
\text {-No static stretching within } 10 \mathrm{~min} \\
\text { before competition }\end{array}$ \\
\hline $\begin{array}{l}\text { An acute bout of static stretching: } \\
\text { effects on force and jumping } \\
\text { performance }\end{array}$ & $\begin{array}{l}\text { Power et } \\
\text { al. }(2004)\end{array}$ & $\begin{array}{l}\text { Cross } \\
\text { sectional } \\
\text { study }\end{array}$ & $\begin{array}{l}\text { SS of the quadriceps resulted in a significant decrease in MVC force } \\
\text { output paralleled by significantly increased sit and reach ROM (both } \\
\text { lasting } 120 \text { min) whereas jumping performance was unaffected SS } \\
\text { may impair isometric force production for up to } 120 \text { min. } \\
\text { Thus, for activities involving maximal force output, it is suggested } \\
\text { that SS such as the methods utilized in the current study be avoided } \\
\text { at least } 120 \text { min pre-performance. }\end{array}$ & $\begin{array}{l}\text { On the jumping performance } \\
\text {-static } \quad \downarrow \\
\text { On isometric force } \\
\text {-static } \quad \downarrow \\
\text { (for } 120 \text { min) } \\
\text { On flexibility } \\
\text { Static } \uparrow\end{array}$ \\
\hline
\end{tabular}




\begin{tabular}{|c|c|c|c|c|}
\hline $\begin{array}{l}\text { The acute effects of different stretching } \\
\text { exercises on jump performance. }\end{array}$ & $\begin{array}{l}\text { Pacheco } \\
\text { et al. } \\
(2011)\end{array}$ & $\begin{array}{l}\text { Cross } \\
\text { sectional } \\
\text { study }\end{array}$ & $\begin{array}{l}\text { Static active stretching in AT can be recommended during the warm- } \\
\text { up for explosive force disciplines. The recommended warm-up in } \\
\text { this context therefore consists of initial general work (low-intensity } \\
\text { training), followed by static stretching with AT, then a series of } \\
\text { dynamic exercises for the various muscle groups, and finally } \\
\text { explosive elastic force exercises appropriate for the sporting } \\
\text { discipline concerned. } \\
\text { The regular performance of stretching exercises has positive long- } \\
\text { term effects and can maintain or increase the flexibility, without } \\
\text { affecting the explosiveness, and can also have a positive effect on } \\
\text { the elastic energy restitution capacity. Those stretching exercises } \\
\text { that are contraindicated for the warm-up may therefore provide long- } \\
\text { term benefits in terms of flexibility training. }\end{array}$ & $\begin{array}{l}\text { On Jump performance } \\
\text {-Static Active (mixed to } \\
\text { dynamic/explosive force } \uparrow \\
\text { On flexibility } \\
\text { - static passive stretching and } P N F \uparrow\end{array}$ \\
\hline $\begin{array}{l}\text { The effect of acute stretching on agility } \\
\text { performance }\end{array}$ & $\begin{array}{l}\text { Van } \\
\text { Gelder et } \\
\text { al. (2011) }\end{array}$ & $\begin{array}{l}\text { Cross } \\
\text { sectional } \\
\text { study }\end{array}$ & $\begin{array}{l}\text { The results of this study indicate that, in comparison to SS or NS, a } \\
\text { bout of acute DS significantly improves performance on a closed } \\
\text { linear running agility test. } \\
\text { Therefore, based on available research, DS as a whole } \\
\text { demonstrates greater athletic performance benefits as a part of } \\
\text { activity warm-up in comparison to SS. } \\
\text { With this in mind, the coach and strength and conditioning } \\
\text { professional should greatly consider preferential use of DS during } \\
\text { pre-activity stretching. }\end{array}$ & \begin{tabular}{ll}
\multicolumn{2}{l}{ On agility performance } \\
-Dynamic & $\uparrow$ \\
-Static & $\downarrow$ \\
-No stretching & $\downarrow$
\end{tabular} \\
\hline
\end{tabular}




\section{DISCUSSION AND CONCLUSION}

In the light of analysed studies we can deduce some reflection.

\section{Stretching and performance}

It has been widely demonstrated that static stretching (SS) exercises performed before strength performances induces an impairment of the performance and impedes the achievement of best results in competitions (Raiola, Tafuri, \& Gomez, 2014). In fact in the warm up phase of sport discipline characterized from explosive muscular power, the execution of stretching performed dynamically should be preferred rather than static stretching.

The majority of the studies analyzed suggests that static stretching produces a significant acute decrement approximately $5-30 \%$ in strength and power production.

A specific research indicates that during the most realistic warm-up condition, as little as 2 minutes of static stretching per muscle group can impair power performance (Young, 2002)

Recently many studies have shown that moderate duration of stretching 15-30 seconds of SS per muscle group does not affect short term muscle strength (Cramer et al., 2007; Ogura et al., 2007). In contrast studies implementing 30, (Winchester, 2008) 60 (Vetter, 2007), or 90 (Robbins, 2008) seconds resulted in decreased jump height.

Another study compared the efficiency of static stretching in respect to dynamic stretching and has shown that sprint performance and horizontal jumps 24 hours after the dynamic stretching (DS) were significantly better than those after the no-stretch and SS. This study highlighted the SS negative effect up to 24 hours post-stretching (Haddad, 2013).

The negative effects of SS resulted also on the isometric strength.

Several previous studies showed that static 5 minutes stretching decreases maximal isometric plantar strength immediately after stretching. However this impairment is restored within 20 minutes after stretching (Mizuno, 2013).

In general warm up includes not only static stretching but also jogging and running. A previous study reported that 5 minutes of running before and after static stretching did not impair performance. Therefore a warm-up consisting of static stretching activity and a series of movements renders the stretching-induced force deficit practically ineffectual.

In addition, taking into consideration the fact that pre-exercise stretching is usually performed at least 20-30 minutes before the start of the competition, and that in practice, the actual time spent stretching for a single site is shorter (15-20 seconds) the disadvantages of static stretching on exercise performance could be probably extremely small.

Therefore, athletes, should not perform static stretching within 10 minutes before competition if they don't want to decrease both the isometric and explosive strength after static stretching.

It's preferable that athletes should perform static stretching about 30 minutes before competitions if they want to increase ROM without inducing the consequences of static stretching (Mizuno, 2013). 
Another study underlined that SS had a significant decrease in MVC force output paralleled by a significant increase in the ROM (both lasting $120 \mathrm{~min}$ ) but the jumping performance was unaffected. Therefore these findings suggest that SS mainly impair isometric force production for up to 120 min and have a minor influence on the jumping performances.

So, especially for activities involving maximal force output, it is suggested that SS be avoided at least 120 min pre-performance.

Therefore the results of researches suggest that the warm up recommended should consist in general work low intensity training followed some static stretching (max 15 seconds) and possible in active tension (AT), then series of dynamic exercises of the various muscle groups and finally explosive elastic force exercises appropriate for the sporting discipline concerned (Rodas, 2009).

In conclusion about the planning of the warm-up before performance the researches indicate, in general, to prefer major use of DS during pre-activity stretching instead of the other stretching techniques.

\section{Stretching and flexibility}

Among the various techniques of muscle stretching, Several studies indicated PNF techniques as the most effective to increase the range of motion. However some studies support that PNF can increase the risk of injury due to the increased tolerance of the lengthening complex muscles and tendons. Fundamental factor to make the PNF effective in increasing the range of motion, is the execution of this technique; it is important the correct posture taken during application.

The ballistic is to be avoided due to the micro-cracks which can cause the level of the connective tissue. Some studies state that ballistic stretching maneuvers may cause injury to the muscle, tendons or ligaments being stretched, but this has not been shown in the literature and it should be used in future comparative purposes. In addition, when ballistic stretching compared with other modes of stretching it may not be as effective or is equally effective for increasing flexibility (Haff, 2006). Nelson and Bandy (2005) recently proposed the use of DS which may be safe and effective alternatives to ballistic stretching.

Passive static stretching for $15-30$ seconds is more effective than the dynamic to improve the range of motion.

In some researches the effectiveness of different protocols in order to improve the flexibility has been evaluated in relation to duration and the type of the programs.

On the basis of many experiments it was found that the most important improvements were achieved by a period of 6 to 90 minutes with multiple daily sessions: this method produces effects that persist for a few weeks and these are related to the posture taken and the timing employed (Vergine, 2008).

For the flexibility training we suggest that it is preferable to dedicate the specific session in the cool-down phase. It should be noted that static passive stretching and PNF would be more indicated during the post effort recovery period, in other words during the return to basal state, because they aid recovery of amplitudes and the drainage of metabolic waste products (primary recovery) and the recovery and normalization of tone 2 hours post-exercise (deep recovery). Those stretching exercises that are unindicated for the warm-up, may therefore provide long term benefits in terms of flexibility training (Pacheco, 2011). 
In conclusion of present studies and reflections on the recent researches indicate guidelines to utilize in the training program. Due to expensiveness of this subject it is not possible to consider the injury risks that is also an important aspect of the stretching on which we should reflect, but it has not been possible to study the researches in this specific topic (Altavilla, Tafuri, \& Raiola, 2014).

We have realize through this review that specific researches in gymnastics are minimum and therefore it is necessary to increase studies about phenomenon of stretching within each single disciplines of gymnastics (Gomez , Rio, D’Anna, 2014).

\section{REFERENCES}

1. Altavilla, G., Tafuri, D., Raiola, G. (2014). Some aspects on teaching and learning by physical activity Sport Science, 7 (1), pp.7-9

2. Arkaev, L.I., \& Sutsilin, N.G. (2004). Gymnastics: How to create Champions. The Theory and methodology of training top class gymnasts. Fizkultura I Sport, Moscow.

3. Behm, D.G., \& Chaouachi A. (2011) A review of the acute effect of static and dynamic stretching on performance. Eur J Appl Physiol 111:2633-2651.

4. Behm, D.G., Button, D.C., \& Butt, J.C. (2011) Factors affecting force loss with prolonged stretching. Can J Appl Physiol 26, pp. 261-272.

5. Bradley, P.S., Olsen, P.D., \& Portas, M.D. (2007) The effect of static, ballistic, and Proprioceptive neuromuscular facilitation Stretching on vertical jump performance. JSCR, 21(1), pp. 223-226.

6. Cramer, J.T., Housh,T.J., Johnson, G.O., Weie J.P., Beck, T.W., \& Coburn, J.W. (2007) An acute bout of static stretching does not affect maximal eccentric isokinetic peak torque, the joint angle at peak torque, mean power, electromyography, or mechanomyography. J Orthop Sports Phys Ther 37, pp. 130-139.

7. Donti, O., Tsolakis, C., \& Bogdanis, G.C. (2014) Effects of Baseline Levels of Flexibility and Vertical Jump Ability on Performance Following Different Volumes of Static Stretching and Potentiating Exercises in Elite Gymnasts. Journal of Sports Science and Medicine, 13, pp. 105-113

8. Frantz, T.L., \& Ruiz, M.D. (2011). Effects of dynamic warm-up on lower body Explosiveness among collegiate Baseball players. Journal of strength and conditioning research. 25 (11)

9. Gomez Paloma, F., Rio, L., \& D'Anna, C. (2014). Physical self-efficacy in women's artistic gymnastic between recreational and competitive level. Journal of human sport and exercise. 9, pp. 341-347, ISSN: 1988-5202

10. Haddad, M., Amir Dridi, A., Chtara, M., Chaouach, A., Wong, D., Behm, D., \& Chamari, K. (2013). Static stretching can impair explosive Performance for at least 24 hours. Journal of strength and conditioning research. 628(1), pp.140-146

11. Haff, G.G. (2006) Roundtable Discussion: Flexibility Training. Strength and Conditioning Journal. pp. 64-85.

12. Magnusson, P., \& Renström, P. (2006) Statement: the role of stretching exercises in sports. European journal of sport science, 6(2), pp.87-91.

13. Mchugh, M. P., Cosgrave, C.H. (2010) To stretch or not to stretch: the role of stretching in injury prevention and performance. Scand j med sci sports, 20, pp. 169-181 john wiley \& sons a/s.

14. Mcmillian, D.J., Josef, H M., Ì Hatler, B., \& Taylor, D.C. (2006). Dynamic vs. Static-stretching warm up: the Effect on power and agility performance. Journal of strength and conditioning research, 20(3), pp. 492-499

15. Mizuno, T., Matsumoto, M., Umemura, Y. (2013) Decrements in Stiff ness are Restored within 10 min. Int J Sports Med; 34, pp. 484-490 
16. Mizuno, T., Matsumoto, M., \& Umemura, Y. (2013). Stretching-induced deficit of maximal Isometric torque is restored within 10 Minutes. Journal of strength and conditioning research. 28(1) pp.147153

17. Nelson, A.G., Guillory, C., Cornwell., \& Kokkonen, J.(2001). Inhibition of maximal voluntary isometric torque production by acute stretching is joint angle specific. Res Q. Exerc. Sport, 72, pp. 68-70

18. Ogura, Y., Miyahara, Y., Naito, H., Katamoto, S., \& Aoki, J. (2007). Duration of static stretching influences muscle force production in hamstring muscles. J. strength Cond Res 21, pp. 788-792.

19. Pacheco, L., Balius, R., Aliste, L., Ppujol, M., \& Pedret, C. (2011) The acute effects of different stretching Exercises on jump performance. Journal of strength and conditioning research, 25(11), pp. 2991-2998.

20. Paradisis, G.P., Pappas P.T, Theodorou, AS., Zacharogiannis, E.G., Skordilis, E.K \& Smirniotou AS (2013). Effects of static and dynamic stretching on Sprint and jump performance in boys and girls. Journal of strength and conditioning research, 28(1) pp. 154-160.

21. Power, K., Behm, D., Cahill F., Carroll, M. \& Young, W. (2004) An acute bout of static stretching: effects on force and jumping performance. Medicine \& Science in Sports \& Exercise $\circledR_{\text {. American }}$ College of Sports Medicine. 0195-9131, (04), pp.3608-1389.

22. Raiola, G., Scassillo, I., Parisi, F., \& Di Tore, P.A. (2013). Motor imagery as a tool to enhance the didactics in physical education and artistic gymnastic, Journal of Human Sport and Exercise, 8 (2), pp. 93-97.

23. Raiola, G., Tafuri, D., \& Gomez Paloma, F. (2014). Physical activity and sport skills and its relation to mind theory on motor control. Sport Science, 7 (1), pp. 52-56

24. Robbins, J.W. And Scheuermann, B.W. (2008). Varying amounts of acute static stretching and its effect on vertical jump performance. J Strength Cond Res, 22, pp. 781-786.

25. Samuel, M.N., Holcomb, W.R., Guadagnoli, M.A., Rubley, M.D., \& Wallmann, H. (2008). Acute effects of static and ballistic Stretching on measures of strength and power. Journal of strength and conditioning research, 22(5), pp. 1422-1428,

26. Sands, W.A., Mcneal, J.R. (1999). Enhancing Flexibility in Gymnastics. USA Gymnastics Online: Technique: Enhancing Flexibility in Gymnastics

27. Shrier, I. (2004). Does Stretching Improve Performance? Clin J Sport Med, 14, (5).

28. Taylor, K.L, Sheppard, J.M., Lee, H. \& Plummer, N. (2009) Negative effect of static stretching restored when combined with a sport specific warm-up component. J Sci Med Sport 12, pp. 657661.

29. Van Gelder, L.H. \& Bartz, S.D. (2011). The effect of acute stretching on agility Performance. Journal of strength and conditioning research. 25(11) pp. 3014-3021.

30. Vergine, V.E., Moretti, B. Stretching e perfomance. Rivista allenatore.

31. Vetter, R.E. (2007) Effects of six warm-up protocols on sprint and jump performance. J Strength Cond Res 21 pp. 819-823.

32. Warren, B., Young, W.B., Behm, D.G. (2002). Should Static Stretching Be Used During a Warm-Up for Strength and Power Activities? Strength and Conditioning Journal.

33. Winchester, J.B., Nelson, A.G., Landin, D., Young, M.A. \& Schexnayder, I.C. (2008) Static Stretching impairs sprint performance in collegiate track and field athletes. J Strength con Res 22, pp. 13-19.

34. Woolstenhulme, M.A, Griffiths, C.M., Woolstenhulme, E.M \& Parcell, A.C. (2006). Ballistic stretching increases flexibility and acute vertical jump height when combined with basketball activity. Journal of strength and conditioning research, 20(4), pp.799-803. 